\title{
Effect of Different Substrates on Yield Potential of Pleurotus spp. in West Bengal
}

\author{
Binoy Gorai and Rishu Sharma* \\ Department of Plant Pathology, Bidhan Chandra Krishi Viswavidyalaya, \\ Mohanpur- West Bengal- 741252 \\ *Corresponding author
}

\begin{tabular}{l} 
K e y w o r d s \\
Pleurotus, Spawn \\
run, Pinning \\
initiation, Paddy \\
Straw, Sugarcane \\
Bagasse, Substrate \\
\hline Article Info \\
\hline $\begin{array}{l}\text { Accepted: } \\
\text { 17 June } 2018 \\
\text { Available Online: } \\
\text { 10 July } 2018\end{array}$ \\
\hline
\end{tabular}

\section{A B S T R A C T}

Three species of Oyster mushroom like, Pleurotus ostreatus, Pleurotus sajor-caju, Pleurotus florida mother culture were procured from DMR, Solan and wild collected strain was collected from Bankura district in West Bengal during the monsoon season of 2017 18. The experimental fruiting trials were conducted under the mushroom house conditions using three substrates viz. Paddy straw, Paddy straw + Sugarcane bagasse (1:1) and Sugarcane bagaase to observe variation in spawn run days, pinning initiation and biological efficiency. Among the four spp/ strains, three Pleurotus spp showed fruiting while the one ssp./strain collected from the wild did not grow under the mushroom house conditions. Also, it was observed that the spawn run was most quick with (12.78 days) and pinning initiation (10.28 days) was most quick with Sugarcane bagasse as substrate. While the biological efficiency was observed to be highest with paddy straw as substrate ranging from 93.2-84.6\% followed by the mixture of Paddy straw and Sugarcane bagasse ranging from 80.4- 75.6 \% and the least was exhibited by sole use of Sugarcane bagasse from $67.6 \%-41.6 \%$. Thus, paddy straw stood out as an outstanding substrate to be used in West Bengal for cultivation of Pleurotus spp.. However, more experiments using more number of substrates are required to be done before any conclusion.

\section{Introduction}

Pleurotus is generally known as Oyster mushroom all over the world and Dhingri in India (Lovkesh et al., 2006). Mushroom has been defined as a macro-fungus with a distinctive fruiting body, which can be epigeous or hypogenous, large enough to be seen with the naked eye and to be picked by hand (Chang and Miles, 1989). Oyster mushroom is one of the most popular edible mushroom and belong to the genus Pleurotus and the family Pleurotaceae. Pleurotus was first cultivated in Germany as a subsistence measure during World War I (Flack, 1917) and is now grown commercially around the world for food. Oyster mushroom is one of the most commonly sought wild mushrooms, though it can also be cultivated on straw and other media. Pleurotus mushrooms are primary decomposers of hardwood trees and are found worldwide. This mushroom has 
basidia with four basidiospores and a tetra polar mating system. Its hyphae have clamp connections in most members of the genus, Fruiting bodies as well as active mycelia of Pleurotus species also possesses a number of therapeutic properties like anti-inflammatory, immune-stimulator and anticancer activity, immunomodulatory, ribonuclease activity and many other activities (Patel et al., 2012). Studies have demonstrated that Oyster mushrooms are healthy foods, which are low in calories and fat, rich in protein, chitin, vitamins and minerals (Manzi et al., 1999). At present, the annual production of button mushroom is $94676 \mathrm{mt}$ and ranks 1st in India and 2nd is Oyster mushroom with a production of $21272 \mathrm{mt}$. West Bengal rank 6th in Oyster mushroom production in India. Pleurotus spp. are popular and widely cultivated throughout the world (Mane et al., 2007; Alam and Raza, 2001; Shah et al., 2004; Flores 2006).

In the present study Pleurotus spp. were cultivated under the mushroom house conditions to determine the most efficient substrate, optimum temperature and other growth parameters suitable for high yield under West Bengal climatic conditions. The mushroom production comes out as an excellent alternative to deal with the economic crisis for the family and society. Representatives of genus Pleurotus form a heterogeneous group of edible species of high commercial importance (Zervakis et al., 2004). The species of genus Pleurotus show great diversity in their adaptation to the varying agro-climatic conditions. This flexible nature of the genus gives it more importance than any other cultivated mushroom (Zadrazil and Dube, 1992).

In India, Pleurotus cultivation was standardized by Bano and Srivastava (1962) utilizing $P$. flabellatus and the first domesticated species was $P$. ostreatus. Later, $P$. sajor-caju gained much importance after
Jandaik and Kapoor (1974) first reported its cultivation on banana pseudo stem and chopped paddy straw. Different substrates have been used by several workers for the cultivation of Pleurotus spp. viz. cotton waste (Chang et al., 1981), jowar straw and groundnut pod (Khandar et al., 1991), wheat straw (Gupta and Langer, 1988), rubber wood waste (Mathew et al, 1991). Thomas et al., (1998) have reported rice straw, as the most widely used substrate in Asia for the cultivation of Pleurotus spp. Mendeel et al., (2005) used cardboard, saw dust and plant fibres for the cultivation of Pleurotus spp.

Similarly Mendez et al., (2005) utilized maize and pumpkin straw as substrates. Several diverse substrates like lignocellulosic materials (Yildiz et al., 2002), unpretreated spent beer grains (Wang et al., 2001), banana and rice straw (Bonatti et al., 2004), various dry weed plants (Das and Mukherjee, 2007), peat moss based substrate (Tawiah and Martin, 2006) have also been used for the cultivation of $P$. ostreatus. Silva et al., (2002) have used cotton peel as substrate for $P$. pulmonarius. Wheat bran supplemented with umbrella plant was used for cultivation of $P$. eryngii (Ohga and Royse, 2004). Thus, the present study was carried out with the objective to determine the high yielding Pleurotus spp. using three substrates viz. Paddy straw, Paddy straw and Sugarcane Bagaase, Sugarcane Bagaase. Also, to determine which Pleurotus spp took minimum and maximum days for spawn run, pinning initiation and biological efficiency.

\section{Materials and Methods}

The experiment on mushroom (Pleurotus spp.) was conducted in the laboratory of plant Pathology, Faculty of Agriculture, Bidhan Chandra Krishi Viswavidyalaya, Mohanpur, Nadia, West Bengal, India, during the year 2017-2018. 
Collection, isolation and maintenance of pure culture

Three species of Oyster mushroom like, Pleurotus ostreatus, Pleurotus sajor-caju, Pleurotus florida mother culture were procured from DMR, Solan (Table 1) and wild collected strain was collected from Bankura district in West Bengal during the monsoon season of 2017-18 i.e July-August. Isolations from the fresh specimen, collected from the wild were made following the standard tissue culture technique (Gomborg, 2002). The sterilized bits were then transferred to Yeastal Potato Dextrose Agar medium slants and incubated at $22 \pm 2^{\circ} \mathrm{C}$. The stock cultures were maintained in the refrigerator at $4^{\circ} \mathrm{C}$. Subculturing of the stock cultures was done after a period of 7-10 days on fresh YPDA slants.

\section{Spawn preparation and spawning}

The procured/ collected Pleurotus spp./ strains were evaluated for their spawning behaviour following the standard technique of (Munjal, 1973). Incubated bottles were shaken at weekly intervals until the mycelium spread completes all over the wheat grains. Fully colonized spawn bottles were then used for the spawning of the bags. Fresh spawns were prepared separately for each experiment. For conducting fruiting trials of various species/strains, cloth bags were filled with 250 gms of wheat straw. The bags were dipped in water overnight and were pasteurized in hot water at $65-70^{\circ} \mathrm{C}$ for 6 hours and then boiled in a drum for 1.5 to 2 hours. Wheat straw was cooled after spreading on a sterilized polythene sheet and tightly filled in polypropylene bags having small holes for aeration. Layer spawning was done and the bags were tied at the top and properly labelled. Spawned bags were kept in the mushroom house (Temperature $22 \pm 2^{\circ} \mathrm{C}$ and relative humidity $80-85 \%$ ) for spawn run. After complete spawn run, the bags were torn opened and hanged with the help of plastic rope on an iron frame for fruiting. The data on spawn run, pinning initiation, fruiting behaviour and yield pertaining to various isolates were recorded.

\section{Substrates preparation and spawning}

For conducting the fruiting trials of different species/strains, substrates used was fresh paddy straw, sugarcane bagasse and paddy straw with sugarcane bagasse (1:1) free from any noticeable contaminants for cultivation. The $250 \mathrm{gm}$ of dry substrate was filled in a cloth bag. The bags were dipped in water overnight and were pasteurized in hot water at $65-70{ }^{\circ} \mathrm{C}$ and then autoclaved at $22 \mathrm{lbs}$ p.s.i and $126{ }^{\circ} \mathrm{C}$ temperature. The substrate was cooled after spreading on a sterilized polythene sheet and tightly filled in polypropylene bags having small holes for aeration. Layer spawning was done and the bags were tied equidistantly at the top on stands made of bamboo and were labeled properly.

\section{Preparation of mushroom bed}

Spawned bags were kept in the mushroom house (Temperature $22 \pm 2{ }^{\circ} \mathrm{C}$ and Relative Humidity $80-85 \%$ ) for spawn run. After complete spawn run, the bags were torn opened and hanged with the help of plastic rope on a bamboo frame for fruiting. The data on spawn run, pinning initiation, fruiting behavior and yield pertaining to various isolates were recorded.

\section{Harvesting of a mushroom}

Harvesting was done when the small primordia converted into a full grown sporophore. Sufficient water was sprinkled to each bed thrice a day. After 1-2 days of cutting of the bag, primordia appearing on the surface, and finally first flush of mushrooms were harvested within 3-5 days. The fully developed fresh mushrooms before they 
curled up were harvested by slight pulling and twisting the fruiting bodies were collected in polythene bags. Successive 2-3 flushes were harvested from the same bed at an interval of 7-10 days. All the beds were allowed to be kept for 45-50 days from the date of spawning.

\section{Weighing of mushroom}

The freshly harvested mushrooms were immediately weighing with the help of single pan balance and moisture per centage was calculated using standard methods (Asharaf, J. et al., 2013).

\section{Yield and biological efficiency}

Total weight of all the fruiting bodies harvested from all the two pickings were measured as total yield of mushroom. The biological efficiency (yield of mushroom per $\mathrm{kg}$ substrate on dry wt. basis) was calculated by the following formula Chang et al., (1981).

B.E. $(\%)=$

Fresh weight of mushroom

------------------------------X 100

Dry weight of substrate

The moisture content of mushroom was calculated by the following formula -

Moisture content $(\%)=$

Weight of fresh sample - weight of dry sample

Weight of fresh sample

\section{Results and Discussion}

\section{Collection and culture}

Mycelial cultures of three species of Pleurotus were procured from DMR, Solan and one was collected wild from Bankura district of West
Bengal during the monsoon months of 201718. Thus a total of four species/strains were taken for further studies as shown in (Table 1).

\section{Morphological studies:}

\section{Fruiting behavioir}

The procured/ collected Pleurotus spp./ strains were evaluated for their spawning behaviour following the standard technique of (Munjal, 1973). The experimental fruiting trials were conducted under the mushroom house conditions showing variation in spawn run days, pinning initiation and biological efficiency (Table 2) (Fig. 1, 2 and 3). Among the four spp/ strains, three Pleurotus spp showed fruiting while the one ssp./strain collected from the wild did not grow under the mushroom house conditions. Also, it was observed that the spawn run (12.78 days) and pinning initiation (15.78 days) was quick in Pleurotus florida (P3) followed by Pleurotus Ostreatus (P1) and Pleurotus sajor-caju (P2). Maximum biological efficiency of $95.20 \%$ per cent was recorded in Pleurotus sajor-caju (P2) followed by $P$. Ostreatus (P1) with $93.20 \%$ on the basis of two flushes using the paddy straw as substrate and a moisture percentage of $89.14 \%$ in Pleurotus sajor-caju (P2) followed by $87.38 \%$ in Pleurotus florida (P3) (Table 3 and 4).

It was observed that the spawn run (10.57 days) and pinning initiation (13.57) was quick in Pleurotus-florida (P3) followed by $P$. Ostreatus (P1) and P. sajor-caju (P2). Maximum biological efficiency of 80.40 per cent was recorded in $P$. sajor-caju followed by 79.80 in $P$. Ostreatus on the basis of two flushes using the Paddy straw and Sugarcane baggase (1:1) as substrate and a maximum moisture percentage of $90.12 \%$ in Pleurotus sajor-caju (P2) followed by $89.56 \%$ in Pleurotus florida (P3) (Fig. 4). 
Table.1 Procured/ collected spp./strains of Pleurotus

\begin{tabular}{|c|c|}
\hline Collection from DMR, Solan & Culture/ Species/ Strain \\
\hline P1 & Pleurotus Ostreatus \\
\hline P2 & Pleurotus sajor-caju \\
\hline P3 & Pleurotus florida \\
\hline Collection from DMR, Solan & Culture/ Species/ Strain \\
\hline P4 & Unidentified \\
\hline
\end{tabular}

Table.2 Fruiting behavior of Pleurotus spp using Paddy straw, Paddy straw+ Sugarcane and Sugarcane Bagasse as substrate

\begin{tabular}{|l|l|l|l|l|l|l|l|l|l|l|l|l|}
\hline P1 & 16 & 16 & 15 & 20 & 20 & 19 & 93.2 & 79.8 & 41.6 & 86.87 & 88.1 & 85.64 \\
\hline P2 & 19 & 19.8 & 18 & 23 & 23.8 & 22 & 95.2 & 80.4 & 57.2 & 89.14 & 90.12 & 88.38 \\
\hline P3 & 12.78 & 10.57 & 10.28 & 23 & 23.8 & 22 & 84.6 & 75.6 & 67.6 & 87.38 & 89.56 & 91.2 \\
\hline
\end{tabular}

Table.3 The mean average yield of Pleurotus spp on different substrates during the Ist flush

\begin{tabular}{|c|r|r|r|r|}
\hline \multicolumn{7}{|c|}{ 1ST HARVESTING } \\
\hline & \multicolumn{1}{|c|}{ PS } & P+S & S & Mean (spp) \\
\hline P1 & 242 & 205 & 124 & 190.333 \\
\hline P2 & 247 & 229 & 169 & 215 \\
\hline P3 & 222 & 196 & 184 & 200.667 \\
\hline Mean (substrate) & 237 & 210 & 159 & \\
\hline CD & Spp & Substrare & Spp X substrate & \\
\hline SE m & 3.456 & 3.456 & 5.986 & \\
\hline
\end{tabular}

Table.4 The mean average yield of Pleurotus spp on different substrates during the Ist flush

\begin{tabular}{|c|r|r|r|r|}
\hline \multicolumn{7}{|c|}{ 2ND HARVESTING } \\
\hline & \multicolumn{1}{|c|}{ PS } & P+S & S & Mean (spp) \\
\hline P1 & 224 & 194 & 84 & 167.333 \\
\hline P2 & 229 & 173 & 119 & 173.667 \\
\hline P3 & 201 & 182 & 154 & 179 \\
\hline Mean (substrate) & 218 & 183 & 119 & \\
\hline & Spp & Substrare & Spp X substrate & \\
\hline CD & 3.405 & 3.405 & 5.897 & \\
\hline SE m & 1.202 & 1.202 & 2.082 & \\
\hline
\end{tabular}


Fig.1 Pleurotus ostreatus cultivation picture in different substrate i) Paddy Straw ii) Paddy Straw +Sugarcane Bagasse iii) Sugarcane Bagasse

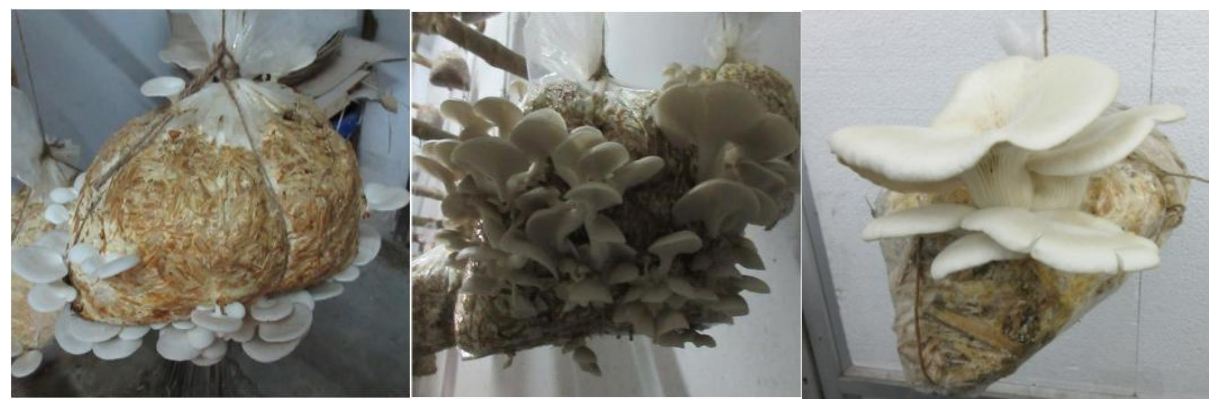

Fig.2 Pleurotus sajor-caju cultivation on different substrates i) Paddy Straw ii) Paddy Straw +Sugarcane Bagasse iii) Sugarcane Bagasse

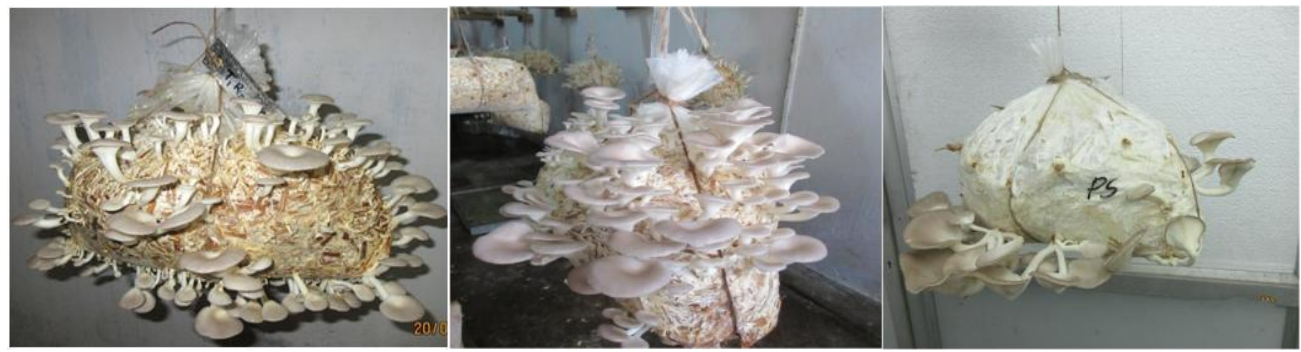

Fig.3 Pleurotus florida cultivation on different substrate i) Paddy Straw ii) Paddy Straw + Sugarcane Bagasse iii) Sugarcane Bagasse
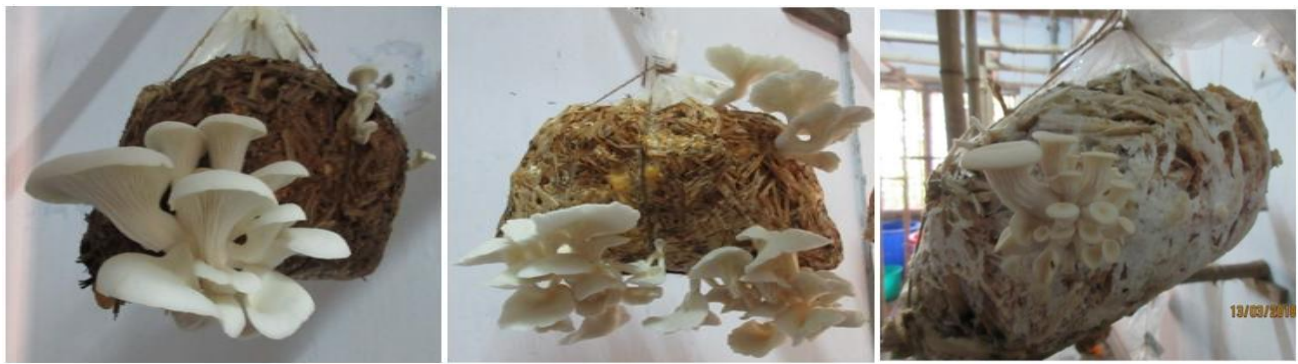

Fig.4 The average yield of Pleurotus spp. using Paddy straw, Paddy straw+ Sugarcane Bageese and Sugarcane Bagasse as substrates

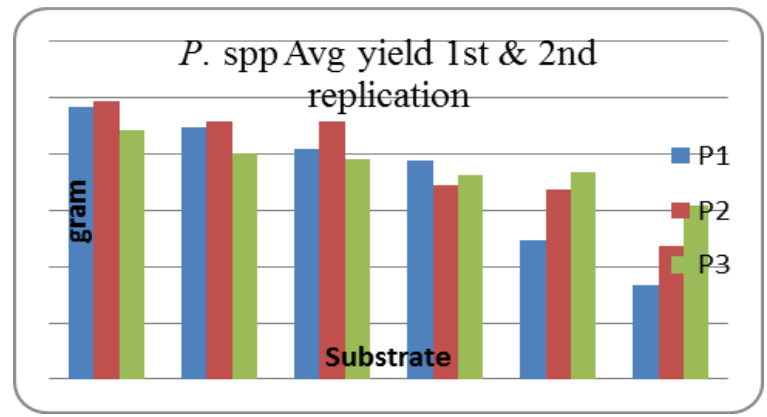


It was observed that the spawn run (10.28 days) and pinning initiation (13.28) was quick in Pleurotus florida (P3) followed by $P$. Ostreatus and $P$. sajor-caju. Maximum biological efficiency of 67.60 percent was recorded in $P$. florida followed by $P$. sajorcaju on the basis of two flushes using the Sugarcane baggase as substrate. and a maximum moisture percentage of $91.20 \%$ in Pleurotus florida (P2) followed by $88.38 \%$ in Pleurotu sajor-caju. Varying period of spawn run and pinning initiation has been reported for various species on different substrates by several workers from time to time (Baysal et al., 2003). The biological efficiency was observed to be highest with paddy straw as substrate ranging from 93.2-84.6\% followed by the mixture of Paddy straw and Sugarcane bagasse ranging from 80.4- $75.6 \%$ and the least was exhibited by sole use of Sugarcane bagasse from $67.6 \%$ - 41.6\%. Thus, paddy straw stood out as an outstanding substrate to be used in West Bengal for cultivation of Pleurotus spp. However, more experiments using more number of substrates are required to be done before any conclusion.

\section{References}

Alam, S.M., Raza, M.S. (2001) Importance of mushrooms. Industry and Economy, NIA, Tandojam, Pakistan.Chang, S.T., Lau, O. W. and Cho, K. Y. (1981) The cultivation and nutritional value of Pleurotus sajorcaju. European Journal of Applied

Ashraf, J., Ali, M.A., Ahmad, W., Ayyub, C. M. and Shafi, J.(2013) Effect of Different Substrate Supplements on Oyster Mushroom (Pleurotus spp.) Production. Food Science and Technology 1(3): 4451.

Bano, Z. and Srivastava, H.C (1962). Studies on the cultivation of Pleurotus species on paddy straw. Food Science 11: 36-38

Bonatti, M., Karnopp, P., Soares, H.M. and Furlan, S. A (2004). Evaluation of Pleurotus ostreatus and Pleurotus sajorcaju nutritional characteristics when cultivated in different lignocellulosic wastes. Food Chemistry 88(3): 425-428.

Das, N. and Mukherjee, M (2007). Cultivation of Pleurotus ostreatus on weed plants. Bioresource Technology 98(14): 27232726.

Flack, R. (1917) Uber dle walkulter des austernpilzes (Agaricus ostreatus) out laubholzstubben. Z. forst-sagdwes. 49: 159-165.

Flores, C. (2006) High-value wild mushrooms a livelihood development strategy for earthquake affected Pakistan. East West Management Institute, New York.

Gamborg, O.L. (2002) Plant tissue culture. Biotechnology. Milestones. In Vitro Cellular \& Developmental Biology. 38(2): 84-92.

Gupta, V.K. and Langer, P.N (1988) Pleurotus florida for upgrading the nutritive value of

wheat straw. Biological wastes 23: 57-64

Jandaik, C. L. and Kapoor, J. N.(1974) Studies on cultivation of Pleurotus sajor-caju. Mushroom Science 9(1): 667-672.

Khandar, R.R., Vaishnav, M.V., Akbari, L.F. and Andhania, J.H (1991). Effect of various plant substrates on sporophore production of Pleurotus sajor-caju. Indian Mushrooms. Proceedings National Symposium on Mushrooms, Thiruvananthpuram, pp. 287-288.

Lovkesh., Beniwal, J. and Pahil, V.S (2006) Physiological and fungistatic interaction studies between Pleurotus spp. and Trichoderma viride, Crop Research Hisar. 32(3): 499-503.

Manzi, P., Gambelli, L., Marconi, S., Vivanti, V. and Pizzoferrato, L. (1999) Nutrients in edible mushrooms. An interspecies comparative study. Food Chem. 65: 477482.

Mane,V. P., Patil, S. S., Syed, A. A. and Baig, M. M. V. (2007) Bioconversion of low quality lignocellulosic agricultural waste into edible protein by Pleurotus sajorcaju (Fr.) Singer. Journal of Zhejiang University of Science. 8(10): 745-751.

Mathew, J.R., Kothandaraman and Thresiama, K.J(1991). Cultivation of oyster mushrooms 
on rubber processing factory waste- a possible solid waste utilization method. Indian Mushrooms Proceedings National Symposium on Mushrooms (1991). Thiruvananthpuram. pp. 97-99

Mendeel, Q.A., Loith, A.A. and Mohamed, S.A (2005). Cultivation of oyster mushrooms (Pleurotus spp.) on various lignocellulosic wastes. World Journal of Microbiology and Biotechnology 21: 601607.

Patel, Y., Naraian, R., and Singh, V..K. (2012) Medicinal Properties of Pleurotus spp (oyster mushroom): A review. World Journal Of Fungal and Plant Biology. 3(1): 01-12.

Ohga, S. and Royse, D (2004). Cultivation of Pleurotus eryngii on umbrella plant (Cyperus alternifolius) substrate. Journal of Wood Science 50(5): 466-469.

Rehana, A., Muhammad, t. and Reham, T (2007). Propagation of Pleurotus sajor- caju

(oyster mushroom) through tissue culture. Pak J. Bot., 39(4): 1383-1386

Shah, Z.A., Ashraf, M., Ishtiaq, M.C. (2004) Comparative study on cultivation and yield performance of oyster mushroom (Pleurotus ostreatus) on different substrates (wheat straw, leaves and sawdust). Pak J Nutr. 3: 158-160.

Silva, S.O., Costa, S.M.G. and Clemente, E (2002). Chemical composition of Pleurotus pulmonarius(Fr.) Quel., substrates and residue after cultivation. Brazilian Archives of Biology and
Technology 45(4): 531-535

Tawiah, W.M. and Martin, A.M (2006). Cultivation of Pleurotus ostreatus mushroom in peat. Journal of the Science of Food and Agriculture 37(9): 833-838.

Thomas, G.V., Prabhu, S.R., Reeny, M.Z. and Bopaiah, B.M (1998). Evaluation of lignocellulosic biomass from coconut palm as substrate for cultivation of Pleurotus sajor-caju. (Fr.) Singer. World Journal of Microbiology and Biotechnology 14: 879-882

Wang, D., Sakoda, A. and Suzuki, M (2001). Biological efficiency and nutritional value of Pleurotus ostreatus cultivation on spent beer grain. Bioresource Technology 78 (3): 293-300.

Yildiz, S., Yildiz, U.C., Gezer, E.D. and Temiz, A (2002) Some lignocellulosic wastes used as raw materials in cultivation of the Pleurotus ostreatus culture mushroom. Process Biochemistry 38 (3): 301-306.

Zervakis, G. I., Monslavo, J. M. and Vilgalys, R (2004). Molecular phylogeny, biogeography

and speciation of the mushroom species Pleurotus cystidiosus and allied taxa. Microbiology 150: 715-726.

Zardazil, F. and Kurtzman, Jr. R. H (1984). The biology of Pleurotus cultivation in the tropics. In Tropical Mushrooms, (Eds. S. T. Chang and T.H. Quimio), The Chinese University Press, HongKong. pp. 227298.

\section{How to cite this article:}

Binoy Gorai and Rishu Sharma, 2018. Effect of Different Substrates on Yield Potential of Pleurotus spp. in West Bengal. Int.J.Curr.Microbiol.App.Sci. 7(07): 2162-2169. doi: https://doi.org/10.20546/ijcmas.2018.707.255 